\title{
Heavy Oil Upgrading in the Presence of Water
}

\author{
Petr M. Eletskii*a, \\ Gleb A. Sosnin ${ }^{\mathrm{a}, \mathrm{b}}$, Olesya O. Zaikina ${ }^{\mathrm{a}}$, \\ Roman G. Kukushkin ${ }^{\mathrm{a}}$ and Vadim A. Yakovlev ${ }^{\mathrm{a}}$ \\ ${ }^{a}$ Boreskov Institute of Catalysis $S B R A S$ \\ 5 Lavrentieva, Novosibirsk, 630090, Russia \\ ${ }^{b}$ Novosibirsk State University \\ 2 Pirogova Str., Novosibirsk, 630090, Russia
}

Received 02.11.2017, received in revised form 22.11.2017, accepted 04.12.2017

\begin{abstract}
In the review, the results of research in the field of heavy crudes upgrading in the presence of water are presented, depending on water phase states at temperatures ca. $150-550{ }^{\circ} \mathrm{C}$. In this temperature region, water can be in the subcritical state (compressed hot water at $T=100-374{ }^{\circ} \mathrm{C}$ and saturated water vapor pressure), in the form of supercritical fluid $\left(T \geq 374{ }^{\circ} \mathrm{C}, P \geq 22.1 \mathrm{MPa}\right.$ ) and in the form of superheated steam (at $P<$ saturated water vapor pressure). Features of the heavy crudes upgrading including mechanisms of water involving in reactions with hydrocarbon feedstocks and model compounds as well as features of the use of catalysts are reviewed.
\end{abstract}

Keywords: upgrading, bitumen, heavy oil, vacuum residue, subcritical water, supercritical water, superheated steam, catalytic steam cracking, aquathermolysis.

DOI: $10.17516 / 1998-2836-0048$.

(c) Siberian Federal University. All rights reserved

* Corresponding author E-mail address: yeletsky@catalysis.ru 


\title{
Облагораживание тяжелого нефтяного сырья \\ в присутствии воды
}

\author{
П.М. Елецкий ${ }^{\mathrm{a}}$, Г.А. Соснин ${ }^{\mathrm{a}, \boldsymbol{\sigma}}$, \\ О.О. Заикина ${ }^{\text {, }, ~ Р . Г . ~ К у к у ш к и н ~}{ }^{\text {, }}$ В.А. Яковлев ${ }^{\text {a }}$ \\ ${ }^{a}$ Институт катализа им. Г. К. Борескова СО РАН \\ Россия, 630090, Новосибирск, пр-кт Ак. Лаврентьева, 5 \\ ${ }^{6}$ Новосибирский государственный университет \\ Россия, 630090, Новосибирск, ул. Пирогова, 2
}

В обзоре систематизированы результаты исследований в области облагораживания нетрадиционного (тяжелого) нефтяного сырья (ТНC) в присутствии воды в зависимости от ее фазового состояния, в температурном интервале $\sim 150-550{ }^{\circ} \mathrm{C}$. В данном температурном диапазоне вода может существовать в субкритическом состоянии $\left(T=100-374{ }^{\circ} \mathrm{C}\right.$ при

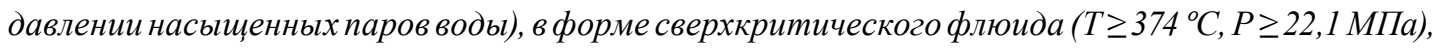
а также в форме перегретого водяного пара (при $P<$ давления насыщения). Рассмотрень особенности прочессов облагораживания ТНС, механизмы участия воды при взаимодействии с углеводородным сырьем и модельными соединениями, а также особенности применения катализаторов в процессе.

Ключевые слова: облагораживание, битум, тяжелая нефть, гудрон, субкритическая вода, сверхкритическая вода, перегретый пар, каталитический паровой крекинг, акватермолиз, крекинг.

\section{Введение}

В связи с увеличением мировой потребности в моторных топливах существенно возрастает необходимость использования в нефтепереработке нетрадиционного тяжелого нефтяного сырья (ТНС), включающего в себя тяжелые нефти, природные битумы, тяжелые остаточные нефтяные фракции (гудрон, мазут), битуминозные пески и горючие сланцы. Высокая вязкость, повышенное содержание серы и металлов, а также асфальтово-смолистых компонентов с характерным для них высоким содержанием серы, азота и кислорода в совокупности с низким содержанием либо полным отсутствием светлых фракций углеводородов осложняют работу с ТНС как на этапе добычи, так и на стадиях транспортировки и дальнейшей переработки [1]. Стоимость только добычи тяжелых нефтей и природных битумов в 3-4 раза выше, чем легких и средних нефтей [2]. Следствием данных особенностей ТНС является то, что запасы нетрадиционного сырья практически не разрабатываются и их доля, которая по оценкам экспертов составляет от 70 до 80 \% в разведанных мировых запасах [3], в дальнейшем будет только увеличиваться. Таким образом, разработка подходов по облагораживанию ТНС с получением маловязкой полусинтетической нефти является актуальной задачей.

Традиционные подходы по переработке ТНС можно разделить на два типа: процессы, основанные на снижении содержания углерода в сырье и насыщении его водородом либо их 
комбинировании [4]. К первому типу можно отнести термический крекинг, деасфальтизацию, висбрекинг и коксование, ко второму - гидрогенизационные процессы [5]. Процессы, основанные на снижении содержания углерода в сырье, в целом, менее затратны, однако характеризуются низким выходом светлых фракций углеводородов и высоким выходом кокса [6]. Процессы, основанные на использовании водорода, наиболее эффективны в получении маловязких качественных продуктов с минимальным выходом нецелевого продукта - кокса, однако они дорогостоящими [7]. С другой стороны, использование водорода для получения полусинтетической нефти из ТНС с целью ее дальнейшей транспортировки непосредственно на местах добычи затруднительно.

Возможной альтернативой гидропроцессам в получении облагороженных продуктов являются процессы, основанные на термических и термокаталитических превращениях ТНС в присутствии воды. Ее применение позволяет получать жидкие продукты более высокого качества по сравнению с термическими процессами, направленными на снижение содержания углерода. Использование воды для облагораживания/предобработки ТНС во многих случаях позволяет снизить выход кокса, уменьшить содержание гетероатомов в жидких продуктах и увеличить соотношение Н/C в них. Таким образом, подходы по облагораживанию ТНС, основанные на использовании воды, можно рассматривать как еще один вариант процессов, направленных на насыщение жидких продуктов облагораживания ТНС водородом.

Вследствие особенностей фазовых состояний воды, в зависимости от температуры и давления (рисунок), по условиям проведения процесса и, следовательно, по типу протекающих химических реакций данные подходы можно условно разделить на акватермолиз в субкритической воде (т.е. жидкой воде при давлении насыщенного водяного пара), крекинг ТНС в сверхкритической воде (СКВ) и крекинг в присутствии водяного пара.

В отличие от традиционных процессов переработки ТНС, основанных на термическом крекинге и гидрокрекинге, механизмы процессов облагораживания углеводородного с использованием воды являются более сложными и на настоящий момент во многом дискуссионными в научной литературе.

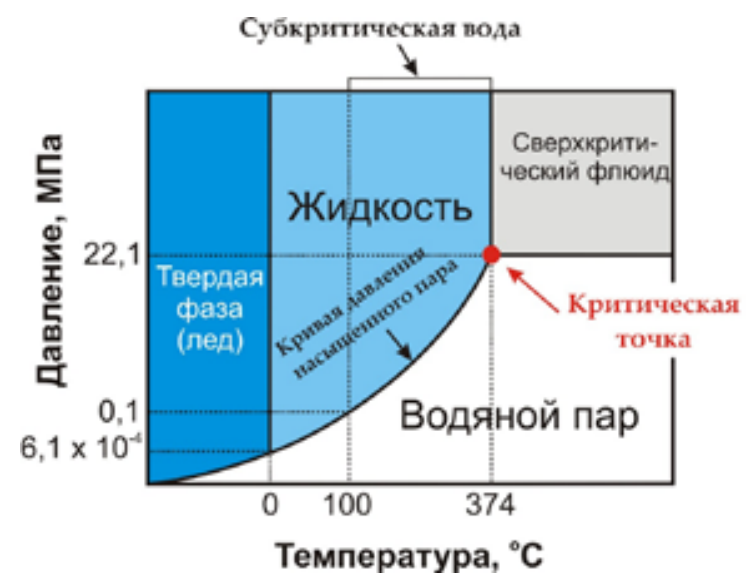

Рис. Фазовая диаграмма воды (схема)

Fig. Phase diagram for water (scheme)

$$
-547-
$$


Цель данного обзора - систематизация данных по облагораживанию ТНС в присутствии воды в ее вышеуказанных фазовых состояниях; обсуждены возможные механизмы облагораживания и участие катализаторов в процессе.

\section{1. Облагораживание тяжелого нефтяного сырья в среде субкритической воды (акватермолиз)}

Понятие «акватермолиз» было введено в 1982 г. Хайном с соавторами [8] как процесс превращения нефтей в среде водяного пара (воды) в присутствии минералов коллектора. Данный процесс можно отнести к одной из разновидностей внутрипластового облагораживания, который проводят от нескольких часов до нескольких суток при относительно невысоких температурах $160-350{ }^{\circ} \mathrm{C}[9]$.

В процессе акватермолиза можно выделить два типа воздействия воды на сырье: физическое и химическое. К физическому воздействию можно отнести непосредственное растворение сырья [10], т. е. его разбавление, что в ходе термических процессов приводит к снижению концентрации свободных радикалов. Тем самым происходит ингибирование процессов агломерации асфальтенов и дальнейшего коксообразования, а также образования смол, из-за присутствия которых вязкость продуктов увеличивается. Способность воды растворять органические соединения связана со снижением ее диэлектрической постоянной при повышении температуры [11]. Таким образом, вода становится средой для протекания различных химических реакций в ходе акватермолиза.

Вода в процессе акватермолиза также способна вступать в различные химические реакции, из которых наиболее значителен при низких температурах гидролиз органических соединений. Данный тип реакций характеризуются тем, что вода является не только растворителем и химическим реагентом, но также и кислотно-основным катализатором [12, 13], поскольку при повышении температуры до $300^{\circ} \mathrm{C}$ она становится одновременно более сильным основанием и кислотой вследствие увеличения ионного произведения. Однако стоит отметить, что при приближении к критической точке вода перестает быть эффективным кислотно-основным катализатором [14]. Для сверхкритической воды характерны процессы, как правило происходящие через образование свободных радикалов $[15,16]$. Помимо каталитической функции, вода непосредственно участвует в химических реакциях. В [17] показана возможность переноса дейтерия из молекул тяжелой воды в продукты превращения битума при температурах от 350 до $530{ }^{\circ} \mathrm{C}$, что может свидетельствовать о протекании реакции ингибирования углеводородных радикалов, образующихся в ходе термического гомолитического разрыва связей С-C (1)-(3), что также обсуждается в $[18,19]$ :

$$
\begin{aligned}
& \mathrm{R}-\mathrm{CH}_{3} \rightarrow \mathrm{R}^{\cdot}+\mathrm{CH}_{3} . \\
& \mathrm{R}^{\cdot}+\mathrm{HOH} \rightarrow \mathrm{RH}+\mathrm{HO}^{\circ} . \\
& \mathrm{RH}+\mathrm{HO}^{\cdot} \rightarrow \mathrm{R}^{\cdot}+\mathrm{HOH}^{\circ} .
\end{aligned}
$$

При температурах менее $175{ }^{\circ} \mathrm{C}$ воздействие на сырье сопровождается преимущественно физическими процессами (плавление твердых парафинов, снижение вязкости вследствие нагрева). Протекание процессов деструкции сераорганических соединений с выделением серо-

$$
-548-
$$


водорода в ходе акватермолиза различных модельных органических субстратов отмечается в диапазоне температур от 200 до $320^{\circ} \mathrm{C}$ [20, 21], поэтому исследуемые субстраты по стабильности в различных реакционных условиях можно условно разделить на следующие группы:

1. Алифатические дисульфиды и тиолы (начало выделения сероводорода до $200{ }^{\circ} \mathrm{C}$ ).

2. Производные тиофена, бензотиазола и алифатические сульфиды (незначительное выделение сероводорода при $\mathrm{T}<200{ }^{\circ} \mathrm{C}$, основное количество $\mathrm{H}_{2} \mathrm{~S}$ выделяется в диапазоне $\left.230-270{ }^{\circ} \mathrm{C}\right)$.

3. Тиофен (устойчив при $\mathrm{T}<200{ }^{\circ} \mathrm{C}$, основное количество $\mathrm{H}_{2} \mathrm{~S}$ выделяется в диапазоне $\left.230-270{ }^{\circ} \mathrm{C}\right)$.

4. Бензотиофен, дибензотиофен (термически стабильны при $\mathrm{T}<330{ }^{\circ} \mathrm{C}$ ).

Данная классификация согласуется с результатами работ Н.К. Ляпиной [22], разделившей нефти на три типа по термической стабильности их серосодержащих компонентов:

1) тиофеновые нефти (содержание сульфидов менее $10 \%$ );

2) сульфидные нефти (содержание меркаптанов не более $5 \%$ );

3) меркаптановые нефти (сопоставимое содержание тиофеновых, сульфидных и меркаптановых сераорганических компонентов).

Таким образом, эффективность процесса акватермолиза нефтяного сырья напрямую зависит от типа перерабатываемой нефти, т. е. определяется содержанием и составом серосодержащих компонентов. С увеличением температуры степень обессеривания увеличивается не только за счет реакций гидролиза, но и благодаря термической деструкции связей C-S.

Ряд исследователей $[15,23]$ допускают возможность протекания реакции водяного газа (4) с образованием водорода, который может в дальнейшем расходоваться в процессах гидрирования, гидрогенолиза и др.:

$$
\mathrm{CO}+\mathrm{H}_{2} \mathrm{O} \rightarrow \mathrm{H}_{2}+\mathrm{CO}_{2}
$$

Источником оксида углерода для данной реакции могут быть кислородсодержащие соединения (альдегиды и кетоны), претерпевающие термодеструкцию в ходе акватермолиза.

В процессе акватермолиза возможно как снижение [10, 24, 25], так и увеличение содержания кислорода в продуктах [26], поскольку, с одной стороны, имеют место гидролитические процессы, характеризующиеся увеличением содержания кислорода, а с другой - происходит термодеструкция моно- и дикислородсодержащих групп с отщеплением $\mathrm{CO}$ или $\mathrm{CO}_{2}$ [27]. Акватермолиз битума при $350{ }^{\circ} \mathrm{C}$ в течение 4 ч приводит к увеличению содержания кислорода в асфальтенах и смолах в 7 и 2 раза соответственно, а также к снижению содержания серы и азота в асфальтенах примерно в 3 раза, что свидетельствует о вовлечении воды в химические превращения высокомолекулярных компонентов нефтей [26]. Таким образом, гидротермальное воздействие воды происходит по наименее устойчивым связям C-N, C-S и C-O.

Интенсификация реакций крекинга С-С-связей с образованием более легких продуктов начинается при температурах от $250^{\circ} \mathrm{C}$. Так, в ходе акватермолиза битуминозного песка Осмингтон Милз (Великобритания) [28] при увеличении температуры процесса с 250 до $275^{\circ} \mathrm{C}$ происходит увеличение выхода метана в 10 раз. Поэтому для получения облегченной нефти в процессе акватермолиза целесообразно поддерживать температуру выше $250{ }^{\circ} \mathrm{C}$.

$$
-549-
$$


Для интенсификации гидротермальных процессов с целью снижения вязкости и повышения глубины обессеривания тяжелого нефтяного сырья используют катализаторы различных типов. По свойствам предшественников и способу получения катализаторов их можно разделить на два типа: водорастворимые (растворы солей, эмульсии и микроэмульсии) и нефтерастворимые.

Вводимые в реакционную среду соединения металлов являются не катализаторами, а их предшественниками, которые претерпевают различные превращения в ходе акватермолиза с образованием каталитически активной металлсодержащей фазы, т. е. катализаторы формируются in situ в нефтяной среде. Полученные таким образом катализаторы интенсифицируют не только реакции гидролиза, но и реакции переноса водорода, реакцию водяного газа и последующее гидрирование сырья. Например, использование солей молибдена, преобразующихся в условиях процесса до сульфида молибдена, активного как в реакциях гидрирования, так и в реакции водяного газа $[29,30]$. Такой in situ подход удобен для осуществления внутрипластового облагораживания сырья, поскольку не сталкивается с проблемой внесения и равномерного распределения гетерогенного катализатора в пласт, а также дезактивации поверхности металлами, содержащимися в тяжелом сырье, и физической дезактивации коксовыми отложениями и механическими примесями (как в случае гетерогенных катализаторов).

\section{1. Применение нефтерастворимых предчественников катализаторов для акватермолиза ТНС}

Эксперименты по акватермолизу нефти Ляохе в присутствии олеата молибдена [31] в статическом режиме (75 г нефти, 25 г воды) в течение 24 ч при $240{ }^{\circ} \mathrm{C}$ показали эффективность данного катализатора в снижении вязкости сырья (на 90 \%). Также в процессе наблюдалось выделение сероводорода, углекислого газа и газообразных углеводородов $\left(\mathrm{C}_{2}-\mathrm{C}_{7}\right)$. Количество насыщенных и ароматических углеводородов увеличивается с уменьшением содержания асфальтенов и смол. Данный факт указывает на то, что некоторые циклические углеводороды могут претерпевать дегидрирование с образованием ароматических соединений. Полученные данные согласуются с [32], где в ходе акватермолиза нефти Ляохе также было отмечено снижение выхода асфальтенов и смол с увеличением выхода продуктов их крекинга $\left(\mathrm{C}_{<25}\right)$.

В $[33,34]$ было проведено исследование каталитической активности сульфонатов железа и меди. Было показано, что при температурах $200-240{ }^{\circ} \mathrm{C}$ в течение 24 ч возможно достижение конверсии высококипящих компонентов на глубину 10-14 мас. \% со снижением содержания серы в смолах и асфальтенах, а также снижение вязкости тяжелой нефти на $90 \%$.

Аналогичные данные были получены при акватермолизе $\left(170{ }^{\circ} \mathrm{C}, 24\right.$ ч) нефти (месторождение «Карамай», Китай) [35] в присутствии различных железосодержащих катализаторов: $\mathrm{Fe}_{2} \mathrm{SO}_{4}, \mathrm{FeCl}_{3}$, нафтената железа и соединения железа и ПАВа типа «гемини». В случае использования предшественника типа «гемини» удается достичь снижения вязкости на 99 \% относительно исходной нефти с конверсией тяжелых компонентов в $6,6 \%$, в то время как снижение вязкости в случае сульфата и хлорида железа происходит всего на 69 и 63 \% соответственно. Существенное различие в вязкости продуктов в данном случае, вероятнее всего, может быть связано с амфифильной природой аниона, а именно его способностью диспергировать асфальтосмолистые агрегаты, что и приводит к снижению вязкости получаемого сырья. Другим преи- 
муществом нефтерастворимых катализаторов является то, что они образуют в нефти истинные растворы и способны проникать в мелкие поры нефтеносной породы, а также распространяться равномерно по всему пласту, не концентрируясь в зоне нагнетания.

\section{2. Применение водорастворимых предчественников катализаторов}

для акватермолиза ТНС

В ряде работ показана эффективность водорастворимых предшественников катализатора в процессе акватермолиза нефтей в статическом режиме при температуре $240{ }^{\circ} \mathrm{C}$ и различном времени проведения процесса $(24,72$ ч) $[36,37]$. В [36] предшественник катализатора представлен в виде смеси сульфатов ванадила, никеля и железа (III), в [37] в качестве катализатора указана соль $\mathrm{Fe}^{2+}$. Приводятся данные о снижении содержания смол и асфальтенов в жидких продуктах по сравнению с экспериментами без катализатора. Снижение вязкости относительно исходного сырья составило 85 и 99 \% соответственно.

Отдельным типом водорастворимых катализаторов можно выделить дисперсные катализаторы, получаемые из эмульсий или микроэмульсий путем термической или химической обработки. Преимуществами дисперсных катализаторов по сравнению с традиционными гранулированными является отсутствие проблем с закупориванием пор катализатора, увеличение доступности высокодисперсных активных центров для крупных молекул реагентов и минимизация диффузионного контроля в ходе реакции [38]. В данной работе также показано существование оптимума концентрации дисперсного молибденсодержащего катализатора (800 ppm), выше которой интенсифицируются процессы коксообразования. Образование кокса может быть связано с агрегированием частиц катализатора с формированием комплексов с асфальтенами и смолами, выступающими в роли нативных ПАВов-стабилизаторов. Стоит отметить, что их способность к агрегированию в более крупные ассоциаты может приводить к оседанию данных частиц в пористых породах и, следовательно, к неравномерному распределению частиц катализатора в коллекторе.

В [39] представлены результаты изучения процесса акватермолиза тяжелой нефти в присутствии наноразмерных катализаторов на основе никеля, железа и меди при температуре 240 и $300{ }^{\circ} \mathrm{C}$ с продолжительностью эксперимента в 6 и 1 сутки соответственно. Снижение вязкости тяжелой нефти было отмечено уже на стадии введения наночастиц катализатора до акватермолиза. Данное уменьшение оказалось более существенным, чем в случае частиц микронного размера, однако нивелировалось при использовании высоких концентраций наночастиц, что авторы объясняют процессами их агрегирования. Водорастворимые катализаторы активны в процессах акватермолиза, однако равномерное введение такого типа катализатора в пласт затруднительно ввиду смачиваемости, неоднородности и пористости нефтеносной породы.

Для улучшения качества продуктов акватермолиза используют различные источники водорода, поскольку нагнетание газообразного водорода в пласт не рассматривается в качестве решения проблемы облагораживания тяжелых нефтей и битумов ввиду опасности данной технологии и труднодоступности молекулярного водорода на промысле. Наиболее распространенными донорами водорода в процессах акватермолиза являются тетралин, муравьиная кислота и СО. 
В [37, 40-42] в качестве донора водорода использовали тетралин. Было установлено, что в его присутствии вязкость и плотность жидких продуктов по сравнению с продуктами акватермолиза без использования водородсодержащих добавок снижаются в более значительной степени. Также было показано, что его использование предотвращает регрессию вязкости продуктов акватермолиза в течение длительного времени. Таким образом, тетралин препятствует рекомбинации свободных радикалов, образующихся при крекинге С-С-связей в ходе акватермолиза. Однако сдерживающим фактором применения данного донора выступает его высокая стоимость и малодоступность на местах добычи.

Использование муравьиной кислоты и СО основано на образовании водорода in situ по реакции водяного газа (4) либо на разложении муравьиной кислоты по реакциям (5)(6):

$$
\begin{aligned}
& \mathrm{HCOOH} \rightarrow \mathrm{CO}+\mathrm{H}_{2} \mathrm{O}, \\
& \mathrm{HCOOH} \rightarrow \mathrm{H}_{2}+\mathrm{CO}_{2} .
\end{aligned}
$$

Термодинамическая возможность протекания данных реакций в интервале температур при 300-800 К показана в [43].

Как утверждается в [44], подача СО в реакционную зону каталитического акватермолиза (катализаторы на основе $\mathrm{Fe}, \mathrm{Co}, \mathrm{Ni}$, Мо и др.) при температуре $240{ }^{\circ} \mathrm{C}$ в течение 7-28 дней приводит к увеличению выхода сероводорода и, следовательно, степени обессеривания, а также к снижению вязкости продукта примерно в два раза.

Авторы [23] приводят результаты экспериментов по акватермолизу $\left(240{ }^{\circ} \mathrm{C}, 24\right.$ ч) нефти Ляохе в присутствии соли никеля с добавлением в качестве донора водорода муравьиной кислоты. Использование доноров водорода авторы объясняют недостаточной глубиной протекания реакции водяного газа для превращения высокомолекулярных компонентов нефтей и снижения вязкости нефти. К дополнительным преимуществам муравьиной кислоты авторы также причисляют ее кислотные свойства: образующийся протон катализирует реакции гидролиза, а при высоких температурах НСООН образует радикалы, которые принимают участие в реакциях переноса водорода и подавлении коксообразования.

Таким образом, акватермолиз наряду с другими процессами внутрипластового облагораживания - низкотемпературным окислением и внутрипластовым горением - является перспективной технологией предобработки тяжелых нефтей и битумов перед транспортировкой по трубопроводу. Однако некоторые особенности данного процесса, а именно зависимость его эффективности от группового состава используемой нефти, нестабильность продуктов, полученных без использования доноров водорода, и незначительные конверсии высокомолекулярных фракций ввиду низких температур процесса, ограничивают применение данного метода в качестве подхода для глубокого облагораживания тяжелого нефтяного сырья. Для увеличения конверсии высокомолекулярных соединений, как было указано ранее, благоприятны более высокие температуры. Вода при таких условиях может находиться либо в форме сверхкритического флюида, либо в виде перегретого пара. Особенности протекания процессов облагораживания тяжелого нефтяного сырья в вышеуказанных условиях будут рассмотрены ниже. 


\section{2. Облагораживание тяжелого нефтяного сырья в сверхкритической воде}

Важной особенностью воды в форме сверхкритического флюида является то, что она существует в температурном интервале, в котором обычно проводят процессы переработки THC традиционными способами $\left(400-500{ }^{\circ} \mathrm{C}\right)$, т.е. когда процессы крекинга углеводородов интенсифицированы в степени, достаточной для достижения глубоких степеней конверсии углеводородного сырья. С другой стороны, в данном температурном диапазоне процессы взаимодействия углеводородов с водой также интенсифицированы, например, по схеме низкотемпературного парциального парового риформинга (НТППР) [45]. Так, равновесная степень деметилирования толуола с образованием бензола в присутствии водяного пара и катализаторов на основе никеля может достигать $73 \%$ при $427{ }^{\circ} \mathrm{C}$ [46]. Помимо этого, по механизму НТППР с водой взаимодействуют алифатические [47-49] и полиароматические углеводороды [48]. Таким образом, преимуществом облагораживания ТНС в СКВ по сравнению с акватермолизом в субкритической воде является возможность достижения более существенной глубины превращений ТНС с вовлечением воды в химическое взаимодействие с углеводородами, а не только с соединениями, содержащими гетероатомы, по механизмам гидролиза.

Другое достоинство сверхкритической воды - ее малая полярность (диэлектрическая проницаемость (ع) СКВ может варьироваться от 2 до 30 [50]) и низкая вязкость при сравнительно высокой плотности [14]. Поэтому СКВ считается хорошим растворителем неполярных органических соединений, в том числе углеводородов, который обладает высокой проницаемостью среды, обеспечивающей хороший массообмен [14]. Вследствие этого облагораживание ТНС в СКВ характеризуется высокой эффективностью, которая повышается при использовании катализаторов [51]. Способность СКВ смешиваться с углеводородами и возможность диспергировать трудно- либо нерастворимые в СКВ высокомолекулярные углеводороды с образованием эмульсий с ними приводит к снижению выхода кокса и увеличению выхода жидких продуктов [52]. Кроме того, СКВ используют для одновременной экстракции и облагораживания битуминозных песков и нефтесланцев [50].

СКВ хорошо смешивается с множеством газов, включая водород и кислород, что дает возможность ее использования в качестве среды для процессов облагораживания ТНС в присутствии окислителей $\left(\mathrm{O}_{2}, \mathrm{H}_{2} \mathrm{O}_{2}\right.$ и др.) $[53,54]$ и водорода, как образующегося in situ, так и газообразного [55].

Применение окислителей для облагораживания ТНС в СКВ позволяет увеличивать эффективность процесса благодаря внедрению кислорода в полиароматические структуры (в частности, асфальтены и смолы), что приводит к повышению их склонности к крекингу [53]. Вторым результатом парциального окисления ТНС в СКВ является образование СО, взаимодействие которого с водой по реакции водяного сдвига (4) приводит к образованию in situ дополнительного водорода, способствуя тем самым повышению эффективности облагораживания. Результатом парциального окисления служит также дополнительное выделение энергии, что может привести к снижению эксплуатационных затрат установок по облагораживанию ТНС [54].

$$
-553-
$$




\section{1. Превращения модельных соединений тяжелого нефтяного сырья}

\section{в условиях сверхкритической воды}

Значительная часть публикаций, посвященных изучению процессов превращений различных типов модельных соединений, направлена на исследование процессов их окисления в среде СКВ в присутствии окислителей $\left(\mathrm{O}_{2}, \mathrm{H}_{2} \mathrm{O}_{2}\right)$. Используемые субстраты являются модельными соединениями биомассы [56, 57], различных промышленных загрязнителей $[58,59]$, остатков сточных вод и пр. [60].

В случае ТНС в качестве модельных соединений используют полиароматические и алифатические углеводороды, а также их производные, содержащие $\mathrm{S}$ и другие гетероатомы. Поскольку полиароматические углеводороды очень стабильны даже в условиях СКВ при $460{ }^{\circ} \mathrm{C}$ [61], для их превращений необходимо использовать источники водорода или кислорода либо катализаторы. Использование окислителей для крекинга полиароматических соединений в условиях гидротермальной обработки в СКВ приводит к внедрению атомов кислорода в структуры их молекул с образованием оксигенатов, которые уже не обладают высокой стабильностью в условиях процесса и более склонны к крекингу.

В [53] было исследовано влияние температуры, соотношения кислорода используемого окислителя $\left(\mathrm{H}_{2} \mathrm{O}_{2}\right)$ к стехиометрическому кислороду $\mathrm{O} / \mathrm{O}_{\text {стех. }}$ (т.е. кислороду, который необходим для полного окисления субстрата), давления и температуры процесса на селективность и выход различных кислородсодержащих производных фенантрена. Было показано, что давление несущественно влияло на конверсию фенантрена, но оказывало влияние на состав газообразных и жидких продуктов. Максимальный выход целевых жидких продуктов, нерастворимых в воде, был зафиксирован при давлении $23,0 \mathrm{MПа,} \mathrm{T}=425{ }^{\circ} \mathrm{C}$ и $\mathrm{O} / \mathrm{O}_{\text {стех. }}=0,2$.

Изучение особенностей процесса окислительной деструкции полиароматических соединений (нафталин, бифенил, фенантрен, флуорен, пирен) и их смесей в суб- и сверхкритической воде, в автоклаве, при $250-380{ }^{\circ} \mathrm{C}$, в присутствии пероксида водорода позволило установить, что в случае проведения процесса в СКВ $\left(\mathrm{T}=380^{\circ} \mathrm{C}\right)$ степень окислительной газификации субстратов с образованием $\mathrm{CO}_{2}$ и $\mathrm{O}_{2}$ в качестве газообразных продуктов может превышать $90 \%$ [62]. Проведение процесса в субкритической воде либо в отсутствие окислителя приводило к снижению степени конверсии. Тем не менее в составе продуктов также были обнаружены молекулы, содержащие на одно или два ароматических кольца меньше, чем у исходных субстратов.

Применение катализаторов состава $\mathrm{NiMo} / \mathrm{SiO}_{2}$ для крекинга антрацена в СКВ в схожих условиях ( $\mathrm{T}=425^{\circ} \mathrm{C}, \mathrm{P}=23,0$ МПа) привело к высокому выходу неполярных продуктов крекинга, нерастворимых в водной фазе, и газообразных продуктов, обогащенных водородом. Было обнаружено, что состав жидких продуктов и выход водорода зависит от состава катализатора [63].

При исследовании процесса крекинга модельного соединения 4-(1-метилнафтил) дибензила в суб- и сверхкритической воде в присутствии катализатора состава 5 \% Ni/C было показано, что введение водорода в процесс способствует снижению выхода кокса и появлению в продуктах крекинга молекул, насыщенных водородом [64]. Глубина превращений в СКВ при $400{ }^{\circ} \mathrm{C}$ была выше, чем в случае крекинга в субкритической воде при $350{ }^{\circ} \mathrm{C}$. 
В [65] была показана эффективность процесса конверсии эйкозана, нафталина и синтетического битума в присутствии и отсутствие кислорода в СКВ при $450-750{ }^{\circ} \mathrm{C}$. Нафталин в условиях СКВ в отсутствие кислорода оставался стабильным до $600{ }^{\circ} \mathrm{C}$.

Алифатические углеводороды в условиях конверсии в СКВ подвергаются крекингу с образованием более коротких алканов и 1-алкенов, соотношение которых зависит от присутствия в среде дополнительных реагентов, а также от плотности СКВ. Так, в [66] эксперименты по конверсии н-гексадекана и полиэтилена в СКВ в автоклавном реакторе при 400 и $420{ }^{\circ} \mathrm{C}$ показали, что добавление кислорода и СО в среду приводит к снижению соотношения алкенов к алканам по сравнению с экспериментами в СКВ в отсутствие СО и $\mathrm{O}_{2}$. Данный результат обусловлен тем, что в результате взаимодействия $\mathrm{CO}$ с СКВ - по реакции водяного газа (4) - образуется водород, который взаимодействует с алкенами с их превращением в алканы. В случае использования кислорода СО образуется в результате парциального окисления субстратов и продуктов крекинга. При окислении н-гексадекана $\mathrm{H}_{2} \mathrm{O}_{2}$ в проточном реакторе при $405-475^{\circ} \mathrm{C}$ и давлении 22,0 МПа в [67] было показано, что соотношение алкенов к алканам зависит от соотношения $\mathrm{O} / \mathrm{C}$ и времени нахождения в реакторе.

Помимо процессов крекинга углеводородов СКВ исследователями также проводится изучение процессов деазотирования [58, 68, 69], десульфидирования [70-74] и деметаллизации [73, $75,76]$ модельных соединений, представляющих собой фрагменты, входящие в состав молекул THC.

\section{2. Облагораживание реального сырья}

в среде сверхкритической воды

Облагораживание тяжелого нефтяного сырья в среде СКВ является комплексным процессом, который помимо химических превращений сырья также включает в себя процессы фракционирования и экстракции углеводородов средой. При облагораживании ТНС часть молекул сырья крекируется и может быть экстрагирована СКВ. Высокомолекулярные углеводороды, в том числе на основе конденсированных полиароматических систем, которые плохо растворимы в СКВ, подвергаются диспергированию в ней с образованием эмульсий. Таким образом, благодаря тому, что СКВ обладает свойствами растворителя, она прекрасно подходит для экстракционного облагораживания такого углеводородного сырья, как битуминозные пески (БП) и нефтяные сланцы (НС). Минеральная часть данного сырья может играть роль катализатора, поэтому получение полусинтетической нефти/битумов из битуминозных песков и нефтяных сланцев обычно проводят без использования катализатора [77-81]. Температура процесса варьируется от 375 до $500{ }^{\circ} \mathrm{C}$, давление $\geq 22,1$ МПа. Исследования процессов облагораживания БП и НС в СКВ показывают следующее:

- экстракция в СКВ проявляет большую эффективность, чем пиролиз и флэш-пиролиз в схожих условиях. При этом полусинтетическая нефть, полученная в результате экстракции СКВ, содержит больше асфальтенов и полярных соединений благодаря взаимодействию СКВ с керогеном [77];

- использование СО приводит к снижению выхода кокса благодаря водороду, образующемуся in situ по реакции водяного газа (4) [80].

$$
-555-
$$


Изучение процессов облагораживания битумов и остатков перегонки нефти в среде СКВ без дополнительных реагентов - источников водорода или кислорода, позволило выявить основные особенности:

- по сравнению термокрекингом ТНС крекинг в среде СКВ приводит к снижению выхода кокса и более высокому выходу жидких продуктов [77, 82];

- степень влияния параметров облагораживания уменьшается в ряду: температура > coотношение вода/ТНС > время > плотность воды [10];

- существенное влияние на эффективность процесса также оказывает выбор режима. Проведение процесса в проточном режиме по сравнению со статическим может приводить к снижению выхода кокса до нулевого [83], благодаря предотвращению рекомбинации образующихся в результате термического крекинга углеводородных радикалов предшественников кокса за счет разрежения среды и диспергирования высококипящих фракций с последующей экстракцией образующихся продуктов крекинга потоком СКВ $[84,85]$.

При облагораживании битумов и остатков перегонки нефти (гудронов, мазутов) для повышения эффективности процесса используют газообразный водород, либо добавки-доноры водорода, либо реагенты, взаимодействующие с водой с образованием водорода в условиях процесса (муравьиную кислоту, СО и пр.). В результате изучения процесса облагораживания битума [86] в СКВ в присутствии муравьиной кислоты и СО при 400-480 ${ }^{\circ} \mathrm{C}$ было показано, что в присутствии НСООН наблюдается максимальная степень превращения асфальтенов при минимальном выходе кокса, т.е. асфальтены в данном случае превращались в жидкие продукты (мальтены), а не в кокс.

Использование катализаторов способствует существенному повышению эффективности процесса облагораживания ТНС. Применяемые катализаторы можно разделить на два типа: катализаторы окислительного крекинга на основе оксидов железа [87] и церия [88] и катализаторы гидрирования на основе $\mathrm{Mo}, \mathrm{Ni}, \mathrm{Co}, \mathrm{Fe}$ [89]. Они могут применяться как в дисперсном виде, так и в виде нанесенных гетерогенных катализаторов (Ni/C [55], $\mathrm{Fe}_{2} \mathrm{O}_{3} / \mathrm{SiO}_{2}$ [87]). Ni-содержащие катализаторы также могут катализировать процессы НТППР углеводородов [45].

В случае применения катализаторов гидрирования их эффективность напрямую зависит от присутствия водорода в процессе вводимого в реакцию облагораживания в газообразной форме либо образующегося in situ. Наиболее эффективными в данном случае являются молибденсодержащие катализаторы, которые в условиях процесса превращаются в $\mathrm{MoS}_{2}$. Их использование приводит к значительному снижению выхода кокса и повышению выхода и качества жидких продуктов [89]. Такие катализаторы также широко применяются в процессах гидрокрекинга ТНС $[29,90]$.

Катализаторы окислительного крекинга для облагораживания ТНС в СКВ интересны тем, что их применение позволяет вовлекать воду как химический агент, за счет ее участия в каталитическом цикле взаимодействия углеводородов с катализатором, при котором катализатор частично восстанавливается углеводородами сырья с потерей решеточного кислорода, а затем реокисляется водой с образованием водорода in situ. СО, образующийся в результате окисления углеводородов решеточным кислородом катализатора, далее может взаимодействовать с водой по реакции водяного газа (4), также приводя к образованию водорода in situ [87]. Основные 
требования к катализаторам окислительного крекинга - устойчивость в средах СКВ и ТНС и возможность изменения степени окисления металлом при восстановлении углеводородами и последующем реокислении водой. На настоящий момент известно, что данным требованиям удовлетворяют оксиды железа и церия, в которых $\mathrm{Fe}$ меняет степень окисления между $\mathrm{Fe}^{2+/ 3+}$, a $\mathrm{Ce}-$ между $\mathrm{Ce}^{3+/ 4+}$ соответственно. В случае применения катализаторов на основе обоих оксидов отмечалось значительное снижение коксообразование и увеличение выхода жидких продуктов $[87,88]$. Участие воды как химического агента в процессе каталитического облагораживания ТНС в СКВ подтверждено путем использования дейтерированной воды [91]. Другим свидетельством каталитического взаимодействия воды является значительное содержание оксидов углерода в газообразных продуктах и увеличение выхода водорода [88].

Несмотря на многочисленные преимущества использования среды СКВ для облагораживания ТНС, сверхкритическая вода характеризуется рядом серьезных недостатков, которые сдерживают распространение методик с ее применением за рамки лабораторных экспериментов. СКВ обладает высокой коррозионностью по отношению к материалам установок и реакторов, в том числе изготовленных из наиболее распространенных марок нержавеющей стали (SS-316 и др.). По данным [14], нержавеющая сталь, никелевые сплавы, титан, благородные металлы и керамика подвержены серьезному разрушению в присутствии солей, кислот и газов, которые хорошо смешиваются с СКВ. Данная особенность сверхкритической воды обусловлена ее возможностью растворять оксидные пленки на поверхности металлов, которые в обычных условиях препятствуют распространению коррозии вглубь метала (например, хром, алюминий).

Стабильность катализаторов в СКВ также является одной из ключевых проблем [63, 92], вследствие чего выбор катализаторов, который и так ограничен, из-за особенностей ТНС сужается в еще большей степени.

Жесткие условия процесса облагораживания ТНС в СКВ ( Т $=400-500{ }^{\circ} \mathrm{C}, \mathrm{P}>22,1$ МПа) приводят к необходимости применения соответствующих конструкционных материалов установок и реакторов, которые при этом также должны быть стабильны в условиях агрессивной СКВ.

Вследствие всех вышеперечисленных недостатков облагораживание ТНС в среде СКВ является дорогостоящим. Потенциальной альтернативой СКВ выступает применение воды в виде водяного пара, который лишен недостатков СКВ.

\section{3. Каталитический паровой крекинг тяжелого нефтяного сырья}

Каталитический паровой крекинг (КПК) ТНС с получением полусинтетической нефти еще одна разновидность облагораживания тяжелого нефтяного сырья в присутствии воды, которая в литературе освещена в меньшей степени, чем процессы в средах суб- и сверхкритической воды. Данный подход лишен таких недостатков облагораживания ТНС в суб- и сверхкритической воде, как низкая глубина превращений сырья и длительность процесса при акватермолизе ТНС (в случае субкритической воды), и высокая коррозионность среды в совокупности с высоким давлением процесса - более 22,1 МПа (в случае СКВ). Однако в случае экспериментов по КПК ТНС в статическом режиме, в котором, как правило проводят облагораживание в суб- и сверхкритической воде, крекинг ТНС в присутствии водяного пара проявляет невысокую эффективность, особенно в отсутствие катализаторов. С другой стороны, из-за высокой вязкости

$$
-557-
$$


ТНС и других присущих ему особенностей эксперименты по КПК в проточном режиме также сопряжены с проблемами. Поэтому в проточном режиме исследователи проводят процесс облагораживания неразбавленного сырья в присутствии дисперсных катализаторов, в реакторах типа сларри, либо прибегают к его разбавлению в ароматических растворителях и используют реакторы с неподвижным слоем катализатора.

КПК ТНС проводят в температурном интервале $375-550^{\circ} \mathrm{C}$, давление может варьироваться от атмосферного до близкого к критическому для воды, массовое соотношение воды к сырью варьируется в интервале от 0,05 до $30: 1$. В данном процессе применяют два типа катализаторов. В случае использования неразбавленного сырья используют дисперсные катализаторы на основе металлов VI и VIII группы ( $\mathrm{Ni}, \mathrm{Fe}, \mathrm{Mo}, \mathrm{Ru})$, которые формируются in situ в ходе процесса из водо- либо нефтерастворимых соединений-прекурсоров. Солипрекурсоры в условиях КПК могут превращаться в сульфиды либо оксиды соответствующих металлов или образовывать смешанные фазы сульфидов и оксидов и участвовать в процессах НТППР, окислительного крекинга углеводородов, гидрирования, гидроочистки и других процессов.

В случае гетерогенных катализаторов и применения ТНС в разбавленной форме используют соосажденные катализаторы окислительного крекинга на основе оксида железа (III), который может быть модифицирован $\mathrm{Al}_{2} \mathrm{O}_{3}, \mathrm{ZrO}_{2}$ и $\mathrm{CeO}_{2}$, либо катализаторы НТППР на основе системы $\mathrm{Ni} / \mathrm{Al}_{2} \mathrm{O}_{3}$ с различными модификаторами активного компонента или носителя.

\section{1. Каталитический паровой крекинг тяжелого нефтяного сырья}

в статическом режиме

Паровой крекинг ТНС в статическом режиме проводят при массовом соотношении воды, как правило, не превышающем $1: 2$. Данное ограничение, по-видимому, связано с тем, что при избыточном количестве воды ее парциальное давление в системе может превысить давление, соответствующее критической точке $(22,1 \mathrm{MПа),} \mathrm{и} \mathrm{вода} \mathrm{перейдет} \mathrm{в} \mathrm{сверхкритический} \mathrm{флюид,}$ т.е. облагораживание ТНС уже будет происходить в среде СКВ, а не водяного пара. При некаталитическом паровом крекинге присутствие воды по сравнению с термокрекингом практически не сказывается на таких показателях процесса, как выходы кокса и жидких продуктов, глубина обессеривания и др. При этом значительного повышения концентрации оксидов углерода (CO, $\mathrm{CO}_{2}$ ) в составе газообразных продуктов, что свидетельствовало бы об интенсификации протекания процессов взаимодействия воды и углеводородов по НТППР либо по другим механизмам, не было обнаружено даже при температурах до $480{ }^{\circ} \mathrm{C}$ [17, 93-95].

Введение дисперсных катализаторов в процесс осуществляют путем добавления в сырье водного раствора их солей-предшественников [95] либо нефтерастворимых соединений - нафтенатов, ацетилацетонатов и других соединений металлов IV или VIII гр. [96], либо через стадию приготовления обратных эмульсий и дисперсий частиц катализатора в сырье с целью лучшего контроля размера частиц $[94,97,98]$. Присутствие катализаторов влияет на процесс парового крекинга по-разному, в зависимости от каталитического металла. Так, использование $\mathrm{Ru}-$ и Ni-содержащих катализаторов приводит к увеличению выхода кокса [95, 97], в то время как катализатор на основе железа способствует его существенному снижению [95]. Использование Мо-содержащих катализаторов не оказывает на выход кокса существенного влияния 
[94]. Содержание серы в жидких продуктах, как правило, снижается более существенно по сравнению с некаталитическими экспериментами.

Помимо влияния катализатора на процессы коксообразования и обессеривания в каталитическом паровом крекинге ТНС в статическом режиме его применение приводит к повышению соотношения Н/C в жидких продуктах по сравнению с жидкими продуктами некаталитического парового крекинга/термокрекинга и/или даже исходным сырьем [94, 96, 97, 99] за счет насыщения жидких продуктов парового крекинга водородом [94, 95]. По эффективности каталитический паровой крекинг можно поместить между гидрокрекингом и каталитическим крекингом в отсутствие воды, поскольку введение воды в процесс крекинга в присутствии катализатора улучшает показатели процесса, в частности выход светлых продуктов $[94,96]$.

Кроме использования дисперсных катализаторов, КПК ТНС в статическом режиме в отдельных случаях применяют для тестирования гетерогенных нанесенных катализаторов с целью определения оптимального состава для последующего их применения в процессе парового крекинга ТНС в проточных реакторах с неподвижным слоем катализатора $[99,100]$.

В целом, следует отметить, что в статическом режиме эффекты влияния воды и катализатора в условиях КПК в большинстве случаев проявляются относительно слабо, что, наиболее вероятно, обусловлено невысоким соотношением воды к ТНС, а также возможной дезактивацией катализатора формирующимися коксовыми отложениями.

\section{2. Каталитический паровой крекинг тяжелого нефтяного сырья}

в реакторах проточного типа в присутствии дисперсных катализаторов

В настоящее время в литературе известно два подхода, разработанных для КПК ТНС в сларри-режиме: процесс с использованием железооксидного грубодисперсного катализатора $[101,102]$ и технология гидровисбрекинга Акваконвершн/Аквапросессинг (Aquaconversion $^{\mathrm{TM}}$ / Aquaprocessing), в котором используется бикомпонентный ультрадисперсный катализатор на основе системы $\mathrm{Ni}+\mathrm{K}$ [103-110].

Паровой крекинг высококипящих фракций $\left(\mathrm{T}_{\text {кип. }}>350^{\circ} \mathrm{C}\right)$ гидрогенизата каменного угля и модельных соединений в присутствии грубодисперсного железного катализатора в проточном реакторе проводили при $430-520{ }^{\circ} \mathrm{C}$, атмосферном давлении и массовом соотношении воды к сырью 1 : 1. Содержание катализатора составляло 2 мас. \% по отношению к сырью. В качестве катализатора был использован порошок $\mathrm{Fe}_{2} \mathrm{O}_{3}$ с размером частиц $<0,1$ мм, удельная поверхность которого составляла $40 \mathrm{~m}^{2} / \Gamma$.

Оксид железа (III) может участвовать в окислительно-восстановительных процессах в средах, содержащих одновременно углеводороды и воду, путем восстановления углеводородами (окислительный крекинг) с последующим реокислением водой, которая может быть в форме перегретого пара либо сверхкритического флюида $[87,111,112]$. Водород, образующийся in situ при реокислении восстановленной железооксидной фазы, может участвовать в насыщении жидких продуктов, тем самым повышая их качество. Исследование отработанного катализатора методом РФА показало, что фаза гематита, из которой состоял свежий катализатор до тестирования, в условиях эксперимента превращается в магнетит $\mathrm{Fe}_{3} \mathrm{O}_{4}$ и пирротит $\mathrm{Fe}_{1-\mathrm{x}} \mathrm{S}$ $(\mathrm{x}=0-0,2)$. 
Максимальный выход жидких продуктов был отмечен при $470{ }^{\circ} \mathrm{C}$, соотношение $\mathrm{H} / \mathrm{C}$ в них составило 1,45 (в исходном сырье - 1,27). При этом в жидких продуктах было обнаружено сниженное содержание гетероатомов таких, как S, N и О. Помимо этого, наблюдалось снижение среднего размера ароматических блоков молекул жидких продуктов по сравнению с исходным сырьем, снижение суммарного содержания парафинов и нафтенов с 24 до 20,8 \%, а также увеличение соотношения $\mathrm{H}_{\mathrm{ap}} / \mathrm{C}_{\text {ap }}$ и длины алифатических заместителей в ароматических кольцах (с 0,76 до 0,78 и с 3,20 до 4,42 соответственно).

Изучение особенностей КПК модельных соединений (тетралин, 1,2-диметилнафталин, 1-нафтол) при $450{ }^{\circ} \mathrm{C}$ показало, что углеводороды в условиях претерпевают типичные реакции НТППР - дегидрирование и деметилирование. Так, в качестве основного продукта КПК тетралина выступал нафталин, 1,2-диметилнафталин превратился в смесь 1-метилнафталина и нафталина. 1-нафтол в условиях процесса претерпевал поликонденсацию и деоксигенацию, также превращаясь в нафталин. При КПК модельных соединений наблюдалось частичное восстановление катализатора (гематита) с превращением в магнетит. Однако в случае проведения крекинга в отсутствие воды гематит восстанавливался в смесь магнетита и металлического железа, что свидетельствует о значимой роли участия воды в процессе облагораживания углеводородного сырья в присутствии железооксидных катализаторов.

Технология гидровисбрекинга ТНС за счет использования воды и ультрадисперсного бикомпонентного катализатора на основе соединений $\mathrm{Ni}$ и К (далее обозначенный как $\mathrm{Ni}+\mathrm{K}$ ) была разработана в конце 1990-х гг. и получила название Аквапросессинга [104-108]. Ее целью является улучшение эффективности традиционного висбрекинга за счет минимальных дополнительных капиталовложений с получением стабильных жидких продуктов, обладающих более высоким качеством по сравнению с продуктами традиционного висбрекинга без катализатора и воды.

Преимуществом технологии Аквапросессинга по сравнению с традиционным висбрекингом является то, что данная технология позволяет получать в одних и тех же условиях жидкие продукты облагораживания, обладающие более высокой стабильностью. Благодаря их повышенной стабильности процесс КПК можно проводить в более жестких условиях - при более высокой температуре и/или меньшей объемной скорости подачи сырья. Это, в свою очередь, приводит к получению стабильных жидких продуктов облагораживания, которые характеризуются более высоким качеством - меньшей вязкостью, более высоким содержанием светлых фракций вследствие повышенной степени конверсии недистиллируемых фракций. Данный результат достигается благодаря введению в процесс висбрекинга воды и бифункционального ультрадисперсного катализатора на основе комбинации металлов $\mathrm{Ni}+\mathrm{K}$. Выбор данной системы был осуществлен на основании скрининга катализаторов, проведенного в $[106,107]$. Применение воды и катализатора способствует насыщению углеводородных радикалов, появляющихся в ходе термических процессов крекинга углеводородов. Таким образом, образующиеся ароматические радикалы не претерпевают конденсацию с образованием асфальтенов, присутствие которых в жидких продуктах может приводить к их дестабилизации. Их насыщение происходит за счет водорода, образующегося из воды в присутствии катализатора $\mathrm{Ni}+\mathrm{K}$, размеры частиц которого составляют несколько десятков нанометров [103]. Предполагается, что К-содержащая компонента активирует процесс диссо- 
циации воды, а Ni-содержащая - процессы НТППР и гидрирования/гидрокрекинга углеводородов [103, 109, 110].

Разработчики данной технологии не приводят результаты исследований конкретного состояния K- и Ni-содержащих компонент данной каталитической системы в условиях процесса, предполагая, что они восстанавливаются до металлов $[109,113]$ либо превращаются в оксиды никеля и калия [110]. Из [97] известно, что соль - предшественник катализатора на основе $\mathrm{Ni}^{2+}$, при ее введении в сырье через стадию приготовления обратной эмульсии ее водного раствора с ТНС в ходе КПК может превращаться в наночастицы фазы состава $\mathrm{Ni}_{9} \mathrm{~S}_{8}$, чему способствует высокое содержание серы, характерное для сырья. Сульфиды никеля являются активными в процессах НТППР углеводородов, что было показано в [45].

Исследования превращений К-содержащей компоненты дисперсного катализатора в условиях КПК ТНС на настоящий момент в литературе не представлены.

Тем не менее, несмотря на то, что авторами технологии Аквапросессинг не было проведено исследований особенностей превращений $\mathrm{Ni}$ - и К-содержащих компонент каталитической системы в среде высокомолекулярного углеводородного сырья и водяного пара в условиях КПК ТНС, ее использование приводит к интенсификации процессов взаимодействия воды с углеводородами сырья, что было подтверждено с помощью использования воды, содержащей изотоп кислорода ${ }^{18} \mathrm{O}[109,110]$.

КПК ТНС в формате Аквапросессинг проводят следующим образом. Компоненты ультрадисперсного катализатора вводят в две стадии. Сначала ТНС смешивают с водным раствором прекурсора К-содержащей компоненты катализатора - КОН, который нейтрализует нафтеновые кислоты, присутствующие в сырье, затем к эмульсии добавляют раствор соли никеля (II) и подвергают ее термообработке при $350-370{ }^{\circ} \mathrm{C}$ с формированием каталитической дисперсии - суспензии частиц катализатора в сырье. Роль нативных ПАВ выполняют соли нафтеновых кислот, а также асфальтены и смолы, присутствующие в ТНС. Помимо них дополнительно также могут быть использованы другие ПАВы, например ТВИН 80 и СПАН 80. В полученной сырьевой дисперсии частиц катализатора в ТНС концентрация Ni может варьироваться от 140 до 500 ppm, К - от 400 до 1200 ppm.

Далее полученную дисперсию используют для экспериментов по КПК, в сравнении с паровым и термическим крекингом. Облагораживание ТНС проводят при $390-445{ }^{\circ} \mathrm{C}$, давлении не более 2,1 МПа, соотношении воды к ТНС 0,05 : 1 по массе. В качестве эксперимента сравнения используют термический крекинг, проведенный в условиях, когда жидкие продукты находятся на границе их стабильности, по отношению к выпадению асфальтенов в осадок. Стабильность жидких продуктов определяется в соответствии со значением Р-индекса, который рассчитывают по следующей формуле:

$$
\text { Р-индекс }=1+\frac{\mathrm{V}(n \text {-цетана (мл) })}{\mathrm{m}(\text { образца (г)) }} \text {. }
$$

Р-индекс определяют путем постепенного добавления $\boldsymbol{H}$-цетана к образцу жидких продуктов и контролируют начало выпадения асфальтенов в осадок с использованием оптического микроскопа. Минимальное значение Р-индекса, при котором образец считается стабильным к выпадению асфальтенов в осадок, составляет 1,15-1,20.

$$
-561-
$$


Таким образом, сначала определяют комбинацию условий термического крекинга (температура и объемная скорость подачи сырья), в которых будет достигаться максимальная степень конверсии с Р-индексом, равным 1,15. Данный эксперимент определяется как базовый, и далее с ним проводится сравнение, насколько можно увеличить степень конверсии сырья, которая выражается в степени превращения недистиллируемых фракций в дистиллируемые, при сохранении Р-индекса, равного 1,15.

Так, в [109] по результатам проведенных экспериментов по облагораживанию арабского гудрона путем термокрекинга, парового крекинга и каталитического парового крекинга в присутствии 140 ppm Ni + 460 ppm К было обнаружено, что в случае КПК при Р-индексе $\leq 1,20$ максимально достижимая степень конверсии сырья составляет $33,5 \%$, в то время как в случае термокрекинга - 29,5 \%. Схожие результаты были получены в [104] при облагораживании гудрона, полученного из нефти венесуэльского месторождения Тиа Хуана Песадо. Степень конверсии гудрона во фракции с $\mathrm{T}_{\text {кип }} \leq 500{ }^{\circ} \mathrm{C}$ удалось повысить с 28,2 до $36,3 \%$ при испытаниях на пилотной установке висбрекинга.

При испытаниях на промышленной установке висбрекинга мощностью 36000 барр/день определяли степень конверсии венесуэльского ТНС в светлые фракции с $\mathrm{T}_{\text {кип }} \leq 350{ }^{\circ} \mathrm{C}$. В данном случае степень конверсии была повышена с 23 до 31 \% по сравнению с висбрекингом. В обоих случаях значения Р-индекса составляли $\geq 1,15$.

Таким образом, паровой крекинг ТНС в проточном режиме в присутствии дисперсных катализаторов включает в себя пример технологии (гидровисбрекинг, Аквапросессинг), которая позволяет более эффективно облагораживать различное ТНС в масштабах, близких к промышленным, чем уже существующая технология (висбрекинг). К недостаткам гидровисбрекинга можно отнести сравнительно небольшую глубину превращений недистиллируемых фракций сырья. Однако для этого, очевидно, необходимо применять более высокое соотношение воды к сырью и, возможно, концентрацию катализаторов либо проводить процесс в реакторах с неподвижным слоем катализатора.

\section{3. Каталитический паровой крекинг тяжелого нефтяного сырья}

в реакторах проточного типа с неподвижным слоем катализатора

В связи с такими особенностями ТНС, как высокая вязкость и склонность к коксообразованию, проведение КПК в проточном реакторе с неподвижным слоем катализатора невозможно без предварительной подготовки сырья. Одним из таких разработанных подходов является разбавление ТНС ароматическими растворителями (бензол и пр.). Данный подход к переработке ТНС путем КПК был предложен Э. Фумото и др. [111]. Эффективность системы $\mathrm{ZrO}_{2} / \mathrm{FeO}_{\mathrm{x}}$ в атмосфере водяного пара обусловлена возможностью образования на ее поверхности активных форм водорода и кислорода из воды. Их образование происходит на поверхности $\mathrm{ZrO}_{2} \mathrm{c}$ последующим спилловером на фазу $\mathrm{FeO}_{x}$, где далее они могут расходоваться в процессе КПК углеводородного сырья [114]. Процесс КПК проводят в реакторе проточного типа с неподвижным слоем катализатора путем подачи $10 \%$-го раствора ТНС в бензоле или толуоле в качестве сырья, в виде восходящего потока.

При оптимизации состава каталитической системы на основе оксидов железа параллельно с условиями процесса были выявлены его следующие особенности. Температура процесса не 
должна превышать $500{ }^{\circ} \mathrm{C}$ [115], при этом должно выполняться необходимое соотношение воды к раствору ТНС ( $\geq 3: 1$ по массе) в случае проведения экспериментов при атмосферном давлении $[112,116]$. Катализатор при этом должен содержать $\mathrm{ZrO}_{2}$ в своем составе $[116,117]$. При сбалансированном составе катализатора (8,2 мас. \% $\mathrm{ZrO}_{2}, 7,0$ мас. \% $\mathrm{Al}_{2} \mathrm{O}_{3}, 84,8$ мас. \% $\mathrm{FeO}_{x}$ ) образование кокса в продуктах процесса наблюдалось при недостаточном соотношении воды к сырью, температуре процесса более $500{ }^{\circ} \mathrm{C}$ [115] либо использовании сырья с повышенным содержанием коксового остатка по Конрадсону $[118,119]$. Кислород из воды и катализатора переходит в состав жидких продуктов в количестве менее $1 \%[112,117,118]$.

Применение высококипящих растворителей (например, 1-метилнафталина) способствует подавлению коксообразования за счет того, что ТНС поступает в слой катализатора в разбавленном состоянии в отличие от толуола и бензола, которые испаряются уже на входе в реактор $[118,119]$.

Помимо этого, было показано, что использование воды в процессе крекинга ТНС снижает соотношение алкенов к алканам в жидких продуктах $[112,117]$ и эффективно в процессах обессеривания дибензотиофена и реального сырья. Сера при этом может превращаться не только в $\mathrm{H}_{2} \mathrm{~S}$, но также в $\mathrm{SO}_{2}[120]$.

Модифицирование катализаторов диоксидом церия улучшает их свойства, а проведение КПК при повышенном давлении (19 МПа, $\left.420^{\circ} \mathrm{C}\right)$ позволяет снизить соотношение воды к ТНС до 20 : 1 без потери катализатором активности. Участие воды в процессе КПК как химического реагента было подтверждено с использованием воды, содержащей изотоп кислорода ${ }^{18} \mathrm{O}$ [121].

Железооксидные катализаторы на основе красного шлама (отхода, образующегося при переработке боксита в процессе Байера), модифицированные $\mathrm{ZrO}_{2}$, могут быть более эффективны, чем синтетические катализаторы схожего состава [99, 122]. Было показано, что в случае использования таких катализаторов, обладающих макромезопористой текстурой, возможно достижение конверсии гудрона 80 \% и увеличение соотношения $\mathrm{H} / \mathrm{C}$ в жидких продуктах до 1,91 (в исходном сырье - 1,34) при сохранении стабильности и способности к регенерации используемых катализаторов с выходом кокса менее 3 мас. \% [122].

Помимо катализаторов на основе оксидов железа, промотированных $\mathrm{ZrO}_{2}$ и другими модификаторами, свою эффективность в процессе КПК ТНС также показали катализаторы НТППР на основе системы $\mathrm{NiK} / \mathrm{Al}_{2} \mathrm{O}_{3}$ [123], в том числе с использованием макромезопористого носителя и $\mathrm{Al}_{2} \mathrm{O}_{3}$, модифицированного смешанным оксидом $\mathrm{CeO}_{2}-\mathrm{ZrO}_{2}[124,125]$, а также кислотные катализаторы на основе смешанных оксидов $\mathrm{TiO}_{2}-\mathrm{ZrO}_{2}$ [126] и модифицированного $\beta$-цеолита [127]. В последнем случае при использовании кислотных катализаторов отмечалось повышенное содержание олефинов в жидких продуктах.

К сравнительным недостаткам данного подхода можно отнести необходимость использования значительного количества воды (минимум $20: 1$ по массе к сырью), а также ароматических растворителей для разбавления ТНС.

\section{Заключение}

Ухудшение качества нефтяного сырья приводит к необходимости разработки подходов к переработке нетрадиционного тяжелого нефтяного сырья. Вследствие дороговизны операций с таким сырьем на всех стадиях - от добычи до переработки на НПЗ - разрабатываемые подходы

$$
-563-
$$


должны быть максимально доступными и в то же время обеспечивать выход жидких продуктов и их качество на приемлемом уровне. Использование воды для добычи, предобработки и облагораживания ТНС является одним из таких подходов, сочетающим в себе немало преимуществ по сравнению с традиционными.

Акватермолиз, наряду с другими процессами внутрипластового облагораживания - низкотемпературным окислением и внутрипластовым горением, является перспективной технологией предобработки тяжелых нефтей и битумов перед транспортировкой по трубопроводу. Однако вследствие малоинтенсивных процессов крекинга углеводородов и их взаимодействия с водой данный подход может быть направлен только на снижение вязкости сырья и применяться для добычи ТНС.

Для повышения глубины превращений тяжелого нефтяного сырья и интенсификации процессов взаимодействия воды и углеводородов необходимо проводить процесс при температурах более $400{ }^{\circ} \mathrm{C}$, когда процессы крекинга углеводородов также идут со значительной скоростью. В температурном интервале $400-500^{\circ} \mathrm{C}$ вода может существовать в форме сверхкритического флюида либо водяного пара. Облагораживание ТНС в сверхкритической воде обладает многими преимуществами за счет того, что СКВ имеет свойства неполярной среды, которая может экстрагировать более легкие углеводороды и диспергировать более тяжелые, нерастворимые в ней, приводя к подавлению коксообразования и увеличения выхода жидких продуктов только за счет данного эффекта. В то же время СКВ хорошо смешивается со многими газами (водород, кислород и др.), что используется для повышения эффективности процесса облагораживания.

Критическим недостатком облагораживания в СКВ является ее высокая коррозионность по отношению к материалам конструкций установок облагораживания и катализаторам. Вследствие этого в данном случае возможно использовать наименее широкий ассортимент катализаторов по сравнению с другими подходами. Еще одним недостатком выступают наиболее жесткие условия процесса (давление $\geq 22,1 \mathrm{MПа).}$

Паровой крекинг ТНС лишен недостатков подходов с использованием суб- и сверхкритической воды, однако вследствие того, что водяной пар не обладает схожими свойствами среды, эффективность парового крекинга ТНС в статическом режиме, в котором обычно проводят эксперименты по облагораживанию в суб- и СКВ, незначительна. В проточном режиме паровой крекинг характеризуется большей эффективностью (как и облагораживание в СКВ), особенно при использовании ТНС в виде раствора в ароматических растворителях.

Следует отметить, что для возможности использования воды в процессе облагораживания как химического агента источника водорода и кислорода как в случае облагораживания в СКВ, так и в случае использования воды в виде пара необходимо использование катализаторов. Наиболее эффективными в данных процессах являются катализаторы окислительного крекинга и низкотемпературного парциального парового риформинга. В первом случае наиболее эффективными показали себя оксиды железа и церия, модифицированные $\mathrm{ZrO}_{2}$. Их эффективность связана с возможностью восстанавливаться углеводородами сырья с отдачей решеточного кислорода и реокисляться водой с возвратом кислорода в решетку и образованием in situ водорода. Диоксид циркония в условиях каталитического парового крекинга атмосфере воды способен расщеплять воду с образованием активных форм водорода и кислорода, что делает его эффективным промотором катализаторов окислительного крекинга. 
В целом, необходимо отметить, что несмотря на то, что подходы по облагораживанию ТНС в СКВ и каталитическому паровому крекингу находятся в стадии становления, они обладают высоким потенциалом в будущем.

\section{Благодарности}

Работа выполнена при финансовой поддержке Министерства образования и науки Российской Федерации: соглашение № 14.607.21.0172, идентификационный номер соглашения RFMEFI60717X0172, название «Разработка новых технологических решений облагораживания углеводородного сырья, минимизирующих или исключающих образование отходов и негативного воздействия на окружающую среду».

\section{Список литературы}

1. Суханов А.А., Петрова Ю.Э. Ресурсная база попутных компонентов тяжёлых нефтей России. Нефтегазовая геология. Теорияипрактика 2008. Т. 3, С. 1-11.[Sukhanov A.A., Petrova Yu.E. Resource base of associated components of heavy oils of Russia. Neftegazovaya geologiya. Teoriya i praktika 2008. Vol. 3, P. 1 - 11 (In Russ.)]

2. ДаниловаЕ. Тяжелые нефти России. The Chemical Journal 2008. Т. 12, С. 34-37. [Danilova Ye. Russian heavy oil. The Chemical Journal 2008. Vol. 12, P. 34 - 37 (In Russ.)]

3. World Energy Council. World Energy Counc 2013 World Energy Resour A Summ 2013. https://www.worldenergy.org/ (accessed September 14, 2017).

4. Анчита Х., Спейт Д. Переработка тяжелых нефтей и нефтяных остатков. Гидрогенизационные процессы. СПб.: ЦОП «Профессия», 2012. 384 с. [Ancheyta J. Speight J.G. Hydroproce ssingofheavyoilsandresidua. Boca Raton, London, New York: CRC Press, 2007. 335 p.]

5. Castañeda L.C., Muñoz J.A.D., Ancheyta J. Current situation of emerging technologies for upgrading of heavy oils. Catalysis Today 2014. V. 220-222, P. 248-273.

6. Sawarkar A.N., Pandit A.B., Samant S.D., Joshi J.B. Petroleum Residue Upgrading Via Delayed Coking: A Review. The Canadian Journal of Chemical Engineering 2007. Vol. 85 (February), P. 1-24.

7. Furimsky E. Hydroprocessing in Aqueous Phase. Industrial \& Engineering Chemistry Research 2013. Vol. 52(50), P. 17695-17713.

8. Hyne J., Clark P., Clarke R., Koo J., Greidanus J., Tyrer J., Verona D. Aquathermolysis of heavy oils. Revista Tecnica Intevep 1982. Vol. 2, P. 87-94.

9. Weissman J.G., Kessler R.V. Downhole heavy crude oil hydroprocessing. Applied Catalysis A: General 1996. Vol. 140 (1), P. 1-16.

10. Cheng Z.M., Ding Y., Zhao L.Q., Yuan P.Q., Yuan W.K. Effects of supercritical water in vacuum residue upgrading. Energy \& Fuels 2009. Vol. 23(6), P. 3178-3183.

11. Rokosova N.N., Rokosov Yu.V., Uskov S.I., Bodoev N.V. Composition and generation of hydrothermal petroleum (a review). Petroleum Chemistry 2001. Vol. 41(1), P. 1-13.

12. Bermejo M.D., Cocero M.J. Supercritical water oxidation: A technical review. AIChE Journal 2006. Vol. 52(11), P. 3933-3951.

13. Akiya N., Savage P.E. Roles of water for chemical reactions in high-temperature water. Chemical Reviews 2002. Vol. 102(8), P. 2725-2750.

$$
-565-
$$


14. Galkin A.A., Lunin V.V. Subcritical and supercritical water: a universal medium for chemical reactions. Russian Chemical Reviews 2005. Vol. 74(1), P. 21-35.

15. Kruse A., Dinjus E. Hot compressed water as reaction medium and reactant. 2. Degradation reactions. Journal of Supercritical Fluids 2007. Vol. 41(3), P. 361-379.

16. Brunner G. Near critical and supercritical water. Part I. Hydrolytic and hydrothermal processes. Journal of Supercritical Fluids 2009. Vol. 47(3), P. 373-381.

17. Dutta RP, McCaffrey WC, Gray MR, Muehlenbachs K. Thermal Cracking of Athabasca Bitumen: Influence of Steam on Reaction Chemistry. Energy \& Fuels 2000;14:671-6. doi:10.1021/ ef990223e.

18. Hoering T.C. Thermal reactions of kerogen with added water, heavy water and pure organic substances. Organic Geochemistry 1984. Vol. 5(4), P. 267-278.

19. Comet P.A., McEvoy J., Giger W., Douglas A.G. Hydrous and anhydrous pyrolysis of DSDP Leg 75 kerogens-A comparative study using a biological marker approach. Organic Geochemistry 1986.Vol. 9(4), P. 171-182.

20. Song Z., Wang M., Batts B.D., Xiao X. Hydrous pyrolysis transformation of organic sulfur compounds: Part 1. Reactivity and chemical changes. Organic Geochemistry 2005. Vol. 36(11), P. $1523-1532$.

21. Song Z., Wang S. Hydrous pyrolysis of organic sulfur compounds: Species and distribution of secondary derivatives. Journal of Analytical and Applied Pyrolysis 2012. Vol. 95, P. 171-179.

22. Lyapina N.K. The Present State of Research into Organosulphur Compounds in Petroleum. Russian Chemical Reviews 1982. Vol. 51(2), P. 189-202.

23. Zhao F., Liu Y., Wu Y., Zhao X., Tan L. Study of catalytic aquathermolysis of heavy oil in the presence of a hydrogen donor. Chemistry and Technology of Fuels and Oils 2012. Vol. 48(4), P. 273-282.

24. Jacobson J.M., Gray M.R. Structural group analysis of changes in Peace River bitumen caused by thermal recovery. Fuel 1987. Vol. 66(6), P. 753-757.

25. Brons G., Siskin M. Bitumen chemical changes during aquathermolytic treatments of Cold Lake tar sands.Fuel 1994. Vol. 73(2), P. 183-191.

26. Кривцов Е.Б., Карпов Ю.О., Головко А.К. Изменение структуры молекул смол и асфальтенов битума меторождения “Баян-Эрхэт” в процессе акватермолиза. Известия Томского политехнического университета 2013. Т. 322(3), С. 86-91.[Krivtsov Ye.B., Karpov Yu.O., Golovko A.K. The changes in structure of resin and asphaltene molecules of bitumen from Bayan-Erhat oil field in a process of aquathermolysis. Izvestiya Tomskogo Politekhnicheskogo Universiteta 2013. Vol. 322(3), P. 86-91 (In Russ.)]

27. Bushnev D.A., Burdel'naya N.S., Shanina S.N., Makarova E.S. Generation of Hydrocarbons and Hetero Compounds by Sulfur-Rich Oil Shale in Hydrous Pyrolysis.Petroleum Chemistry 2004. Vol. 44(6), P. 416-425.

28. Montgomery W., Court R.W., Rees A.C., Sephton M.A. High temperature reactions of water with heavy oil and bitumen: Insights into aquathermolysis chemistry during steam-assisted recovery. Fuel 2013. Vol. 113, P. 426-34.

29. Panariti N., Del Bianco A., Del Piero G., Marchionna M., Carniti P. Petroleum residue upgrading with dispersed catalysts. Part 2. Effect of operating conditions. Applied Catalysis A: General 2000. Vol. 204(2), P. 215-222. 
30. Jia L., Alghamdi A., Ng F.T.T. Nanocatalysis for Fuels and Chemicals. In: Nanocatalysis for Fuels and Chemicals, Vol. 1092, Washington, DC: American Chemical Society; 2012, P. 37.

31. Wen S., Zhao Y., Liu Y., Hu S. A Study on Catalytic Aquathermolysis of Heavy Crude Oil During Steam Stimulation. Int. Symp. Oilf. Chem., Houston, Texas, USA: Curran Associates, Inc.; 2007, P. 417.

32. Hongfu F., Yongjian L., Liying Z., Xiaofei Z. The study on composition changes of heavy oils during steam stimulation processes. Fuel 2002. Vol. 81(13), P. 1733-1738.

33. Chen Y., Wang Y., Wu C., Xia F. Laboratory Experiments and Field Tests of an Amphiphilic Metallic Chelate for Catalytic Aquathermolysis of Heavy Oil. Energy \& Fuels 2008. Vol. 22(3), P. 1502-1508.

34. Chao K., Chen Y., Liu H., Zhang X., Li J. Laboratory experiments and field test of a difunctional catalyst for catalytic aquathermolysis of heavy oil. Energy \& Fuels 2012. Vol. 26(2), P. $1152-1159$.

35. Chen Y., Yang C., Wang Y. Gemini catalyst for catalytic aquathermolysis of heavy oil. Journal of Analytical and Applied Pyrolysis 2010. Vol. 89(2), P. 159-165.

36. Fan H.-F., Liu Y.-J., Zhong L.-G. Studies on the Synergetic Effects of Mineral and Steam on the Composition Changes of Heavy Oils. Energy \& Fuels 2001. Vol. 15(6), P. 1475-1479.

37. Jiang S., Liu X., Liu Y., Zhong L. In Situ Upgrading Heavy Oil by Aquathermolytic Treatment under Steam Injection Conditions. Proc. SPE Int. Symp. Oilf. Chem., The Woolands, Texas: Society of Petroleum Engineers; 2005, P. 8.

38. Kennepohl D., Sanford E. Conversion of Athabasca Bitumen with Dispersed and Supported Mo-Based Catalysts as a Function of Dispersed Catalyst Concentration. Energy \& Fuels 1996. Vol. 10(1), P. 229-234.

39. Shokrlu Y.H., Babadagli T. Viscosity reduction of heavy oil/bitumen using micro- and nanometal particles during aqueous and non-aqueous thermal applications. Journal of Petroleum Science and Engineering 2014. Vol. 119, P. 210-220.

40. Liu Y., Fan H. The effect of hydrogen donor additive on the viscosity of heavy oil during steam stimulation. Energy \& Fuels 2002. Vol. 16(4), P. 842-846.

41. Ovalles C., Rodríguez H. Extra heavy crude oil downhole upgrading using hydrogen donors under cyclic steam injection conditions: Physical and numerical simulation studies. Journal of Canadian Petroleum Technology2008.Vol. 47(1), P.43-50.

42. Petrukhina, N.N. et. al. Conversion processes for high-viscosity heavy crude oil in catalytic and noncatalytic aquathermolysis. Chemistry and Technology of Fuels and Oils 2014. Vol. 50(4), P. 315-326.

43. Lyubimenko V.A., Petrukhina N.N., Tumanyan B.P., Kolesnikov I.M. Thermodynamic parameters of conversion reactions of some heavy oil components under the action of steam and heat. Chemistry and Technology of Fuels and Oils 2012. Vol. 48(4), P. 299-301.

44. Patent 4506733 US. Hyne J.B., Clark P.D. Additive for inclusion in a heavy oil reservoir undergoing steam Injection. Publ. Date 26.03.1985.

45. Duprez D. Selective steam reforming of aromatic compounds on metal catalysts. Applied Catalysis A: General 1992. Vol. 82(2), P. 111-157.

46. Maslyanskii G., Rabinovich G. Demethylation of toluene by conversion with steam. Petroleum Chemistry U.S.S.R. 1962. Vol. 1(1), P.104-109.

$$
-567-
$$


47. Rabinovich G.L., Treiger L.M., Maslyanskii G.N. Conversions of n-heptane during interaction with steam with an alumina-rhodium catalyst. Petroleum Chemistry U.S.S.R. 1973. V. 13(3), P. 199205.

48. Kim C. Noble metal-catalyzed water-hydrocarbon reaction paths. Journal of Catalysis 1978. Vol. 52 (1), P. 169-175.

49. Wang X., Gorte R.J. A study of steam reforming of hydrocarbon fuels on Pd/ceria. Applied Catalysis A: General 2002. Vol. 224(1-2), P. 209-218.

50. Li N., Yan B., Xiao X.-M. A Review of Laboratory-Scale Research on Upgrading Heavy Oil in Supercritical Water. Energies 2015. Vol. 8(8), P. 8962-8989.

51. Golmohammadi M., Ahmadi S.J., Towfighi J. Catalytic cracking of heavy petroleum residue in supercritical water: Study on the effect of different metal oxide nanoparticles. The Journal of Supercritical Fluids 2016. Vol. 113, P. 136-143.

52. Arcelus-Arrillaga P., Pinilla J.L., Hellgardt K., Millan M. Application of Water in Hydrothermal Conditions for Upgrading Heavy Oils: A Review. Energy \& Fuels 2017. Vol. 31(5), P. 4571-4587.

53. Arcelus-Arrillaga P., Hellgardt K., Millan M. Effect of process conditions on the hydrothermal partial oxidation of phenanthrene as a heavy oil model structure. Fuel 2017. Vol. 209, P. 434-441.

54. Sato T., Adschiri T., Arai K., Rempel G.L., Ng F.T. Upgrading of asphalt with and without partial oxidation in supercritical water. Fuel 2003. Vol. 82(10), P. 1231-1239.

55. Gai X.-K., Arano H., Lu P., Mao J.-W., Yoneyama Y., Lu C.-X. et al. Catalytic bitumen cracking in sub- and supercritical water. Fuel Processing Technology 2016. Vol. 142, P. 315-318.

56. Jin H., Lu Y., Guo L., Cao C., Zhang X. Hydrogen production by partial oxidative gasification of biomass and its model compounds in supercritical water. International Journal of Hydrogen Energy 2010. Vol. 35 (7), P. 3001-3010.

57. Güvenatam B., Heeres E.H.J., Pidko E.A., Hensen E.J.M. Decomposition of lignin model compounds by Lewis acid catalysts in water and ethanol. Journal of Molecular Catalysis A: Chemical 2015. Vol. 410, P. 89-99.

58. Gong Y., Guo Y., Wang S., Song W. Supercritical water oxidation of Quinazoline: Effects of conversion parameters and reaction mechanism. Water Research 2016. Vol. 100, P. 116-125.

59. Rogacki G., Zawadzka A. Kinetics of anaerobic decomposition of 4-nitrotoluene-2-sulfonic acid in sub- and supercritical water. The Journal of Supercritical Fluids 2017. Vol. 128, P. 1-5.

60. Gong M., Nanda S., Romero M.J., Zhu W., Kozinski J.A. Subcritical and supercritical water gasification of humic acid as a model compound of humic substances in sewage sludge. The Journal of Supercritical Fluids 2017. Vol.119, P. 130-138.

61. Katritzky A.R., Barcock R.A., Balasubramanian M., Greenhill J.V., Siskin M., Olmstead W.N. Aqueous High-Temperature Chemistry of Carbo- and Heterocycles. 20. Reactions of Some Benzenoid Hydrocarbons and Oxygen-Containing Derivatives in Supercritical Water at $460{ }^{\circ} \mathrm{C}$. Energy \& Fuels 1994. Vol. 8(2), P. 487-497.

62. Onwudili J.A., Williams P.T. Flameless supercritical water incineration of polycyclic aromatic hydrocarbons. International Journal of Energy Research 2006. Vol. 30(7), P. 523-533.

63. Reina T.R., Yeletsky P., Bermúdez J.M., Arcelus-Arrillaga P., Yakovlev V.A., Millan M. Anthracene aquacracking using $\mathrm{NiMo} / \mathrm{SiO}_{2}$ catalysts in supercritical water conditions. Fuel 2016. Vol. 182, P. $740-748$. 
64. Tan L., Erdenebaatar O., Liu G., Yamane N., Ai P., Otani A. et al. Catalytic cracking of 4-(1-naphthylmethyl)bibenzyl in sub- and supercritical water. Fuel Processing Technology 2017. Vol. 160, P. 34-38.

65. Vostrikov A.A., Dubov D.Yu., Psarov S.A.The Effect of Thermal Explosion in a Supercritical Water. Technical Physics Letters 2001. Vol. 27(10), P. 847-849.

66. Watanabe M., Mochiduki M., Sawamoto S., Adschiri T., Arai K. Partial oxidation of n-hexadecane and polyethylene in supercritical water. The Journal of Supercritical Fluids 2001. Vol. 20(3), P. 257-266.

67. Alshammari Y.M., Hellgardt K. Partial oxidation of n-hexadecane through decomposition of hydrogen peroxide in supercritical water. Chemical Engineering Research and Design 2015. Vol. 93, P. 565-575.

68. Gong Y., Guo Y., Wang S., Song W., Xu D. Supercritical water oxidation of quinazoline: Reaction kinetics and modeling. Water Research 2017. Vol. 110, P. 56-65.

69. Yuan P.Q., Cheng Z.M., Zhang X.Y., Yuan W.K. Catalytic denitrogenation of hydrocarbons through partial oxidation in supercritical water. Fuel 2006. Vol. 85(3), P. 367-373.

70. Patwardhan P.R., Timko M.T., Class C.A., Bonomi R.E., Kida Y., Hernandez H.H. et al. Supercritical water desulfurization of organic sulfides is consistent with free-radical kinetics. Energy and Fuels 2013. Vol. 27(10), P. 6108-6117.

71. Kida Y., Class C.A., Concepcion A.J., Timko M.T., Green W.H. Combining experiment and theory to elucidate the role of supercritical water in sulfide decomposition. Physical chemistry chemical physics: PCCP 2014. Vol. 16(20), P. 9220-9228.

72. Ates A., Azimi G., Choi K.H., Green W.H., Timko M.T. The role of catalyst in supercritical water desulfurization. Applied Catalysis B: Environmental 2014. Vol. 147, P. 144-155.

73. Vogelaar B.M., Makkee M., Moulijn J.A. Applicability of supercritical water as a reaction medium for desulfurisation and demetallisation of gasoil. Fuel Processing Technology1999. Vol. 61(3), P. 265-277.

74. Adschiri T., Shibata R., Sato T., Watanabe M., Arai K. Catalytic Hydrodesulfurization of Dibenzothiophene through Partial Oxidation and a Water-Gas Shift Reaction in Supercritical Water. Industrial \& Engineering Chemistry Research 1998. Vol. 37 (7), P. 2634-2638.

75. Mandal P.C., Wahyudiono, Sasaki M., Goto M. Nickel removal from nickel etioporphyrin (Ni-EP) using supercritical water in the absence of catalyst. Fuel Processing Technology 2012. Vol. 104, P. 67-72.

76. Mandal P.C., Wahyudiono, Sasaki M., Goto M. Nickel removal from nickel-5,10,15,20tetraphenylporphine using supercritical water in absence of catalyst: A basic study. Journal of Hazardous Materials 2011. Vol. 187(1-3), P. 600-603.

77. Yanik J., Yüksel M., Sağlam M., Olukçu N., Bartle K., Frere B. Characterization of the oil fractions of shale oil obtained by pyrolysis and supercritical water extraction. Fuel 1995. Vol. 74(1), P. $46-50$.

78. Funazukuri T., Yokoi S., Wakao N. Supercritical fluid extraction of Chinese Maoming oil shale with water and toluene. Fuel 1988. Vol. 67(1), P. 10-14.

79. Olukcu N., Yanik J., Saglam M., Yuksel M., Karaduman M. Solvent Effect on the Extraction of Beypazari Oil Shale. Energy \& Fuels 1999. Vol. 13 (4), P. 895-902. 
80. Berkowitz N., Calderon J. Extraction of oil sand bitumens with supercritical water. Fuel Processing Technology 1990. Vol. 25(1), P. 33-44.

81. Meng, Hu H., Zhang Q., Ding M. Extraction of Tumuji Oil Sand with Sub- and Supercritical Water. Energy \& Fuels 2006. Vol.20(3), P. 1157-1160.

82. Han L., Zhang R., Bi J., Cheng L. Pyrolysis of coal-tar asphaltene in supercritical water. Journal of Analytical and Applied Pyrolysis 2011. Vol. 91(2), P. 281-287.

83. Cantero D.A., Dolores Bermejo M., José Cocero M. Reaction engineering for process intensification of supercritical water biomass refining. The Journal of Supercritical Fluids 2015. Vol. 96, P. 21-35.

84. Fedyaeva O.N., Shatrova A.V., Vostrikov A.A. Effect of temperature on bitumen conversion in a supercritical water flow. The Journal of Supercritical Fluids 2014. Vol. 95, P. 437-443.

85. Morimoto M., Sugimoto Y., Sato S., Takanohashi T. Bitumen Cracking in Supercritical Water Upflow. Energy \& Fuels 2014. Vol. 28(2), P. 858-861.

86. Sato T., Mori S., Watanabe M., Sasaki M., Itoh N. Upgrading of bitumen with formic acid in supercritical water. The Journal of Supercritical Fluids 2015. Vol. 55, P. 232-240.

87. Hosseinpour M., Ahmadi S.J., Fatemi S. Successive co-operation of supercritical water and silica-supported iron oxide nanoparticles in upgrading of heavy petroleum residue: Suppression of coke deposition over catalyst. The Journal of Supercritical Fluids 2015. Vol. 100, P. 70-78. doi:10.1016/j. supflu.2015.02.013.

88. Dejhosseini M., Aida T., Watanabe M., Takami S., Hojo D., Aoki N. et al. Catalytic Cracking Reaction of Heavy Oil in the Presence of Cerium Oxide Nanoparticles in Supercritical Water. Energy \& Fuels 2013. Vol. 27(8), P. 4624-4631.

89. Jian C., Yihong L., Yunhua L., Guohe Q. Hydrocracking of Gudao Residual Oil with Dispersed Catalysts Using Supercritical Water-Syngas as a Hydrogen Source. Petroleum Science and Technology 2005. Vol. 23(11-12), P. 1453-1462.

90. Khadzhiev S.N., Kadiev Kh.M., Kadieva M.Kh. Synthesis and properties of nanosized systems as efficient catalysts for hydroconversion of heavy petroleum feedstock. Petroleum Chemistry 2014. Vol. 54(5), P. 327-351.

91. Hosseinpour M., Fatemi S., Ahmadi S.J. Deuterium tracing study of unsaturated aliphatics hydrogenation by supercritical water in upgrading heavy oil. Part II: Hydrogen donating capacity of water in the presence of iron(III) oxide nanocatalyst. The Journal of Supercritical Fluids 2016. Vol. 110, P. 75-82.

92. Savage P.E. A perspective on catalysis in sub- and supercritical water. The Journal of Supercritical Fluids 2009. 47(3), P. 407-414. doi:10.1016/j.supflu.2008.09.007.

93. Nhieu P., Liu Q., Gray M.R. Role of water and fine solids in onset of coke formation during bitumen cracking. Fuel 2016.Vol. 166, P. 152-156.

94. Mironenko O.O., Sosnin G.A., Eletskii P.M., Gulyaeva Yu.K., Bulavchenko O.A., Stonkus O.A. et al. A Study of the catalytic steam cracking of heavy crude oil in the presence of a dispersed molybdenum-containing catalyst. Petroleum Chemistry 2017. Vol. 57(7), P. 618-629.

95. Clark P.D., Kirk M.J. Studies on the upgrading of bituminous oils with water and transition metal catalysts. Energy \& Fuels 1994. Vol. 8(2), P. 380-387.

96. Ahn H.K., Park S.H., Sattar S., Woo S.I. Vacuum residue upgrading through hydroprocessing with subcritical water. Catalysis Today 2016. Vol. 265, P. 118-123. 
97. Eletskii P.M., Mironenko O.O., Sosnin G.A., Bulavchenko O.A., Stonkus O.A., YakovlevV.A. Investigating the process of heavy crude oil steam cracking in the presence of dispersed catalysts. II: Investigating the effect of $\mathrm{Ni}$-containing catalyst concentration on the yield and properties of products. Catalysis in Industry 2016. Vol. 8(4), P. 328-335.

98. Khadzhiev S.N., Kadiev K.M., Kadieva M.K. Synthesis and properties of nanosized systems as efficient catalysts for hydroconversion of heavy petroleum feedstock. Petroleum Chemistry 2014. Vol. 54(5), P. 323-346.

99. Lee H.S., Nguyen-Huy C., Pham T.-T., Shin E.W. $\mathrm{ZrO}_{2}$-impregnated red mud as a novel catalyst for steam catalytic cracking of vacuum residue. Fuel 2016. Vol. 165, P. 462-467.

100. Kondoh H., Nakasaka Y., Kitaguchi T., Yoshikawa T., Tago T., Masuda T. Upgrading of oil sand bitumen over an iron oxide catalyst using sub- and super-critical water. Fuel Procesing Technology 2016. Vol. 145, P. 96-101.

101. Sharypov V.I., Kuznetsov B.N., Beregovtsova N.G., Baryshnikov S.V., Sidel'nikov V.N. Steam cracking of coal-derived liquids and some aromatic compounds in the presence of haematite. Fuel 1996. Vol. 75(5), P. 791-794.

102. Patent 2132356RU.Sharypov V.I., Beregovtsova N.G., Baryshnikov S.V., Kuznetsov B.N. Method of thermo-catalytically processing gigh-boiling hydrocarbon fractions. Publ. Date 27.06.1999.

103. Patent Application Publication 2013/0015100 US. Pereira Almao P., Trujilo G.L., Peluso E., Galarraga C., Sosa C., Scott Algara C. et al. Systems and Methods for Catalytic Steam Cracking of Non-Asphaltene Containing Heavy Hydrocarbons. Publ. Date 17.01.2013.

104. Marzin R., Pereira P., McGrath M.J., Feintuch H.M., Thompson G., Houde E. New residue process increases conversion, produces stable residue in Curacao refinery. Oil\& Gas Journal 1998. Vol. 96(44), P. 79-86.

105. Pereira P., Flores C., Zbinden H., Guitian J., Solari R.B, Feintuch H. et al. Aquaconversion technology offers added value to E. Venezuela synthetic crude oil production. Oil \& Gas Journal 2001. Vol. 99(20), P. 79-85.

106. Patent 5688395 US. Carrazza J., Pereira P., Martinez N. Process and catalyst for upgrading heavy hydrocarbon. Publ. Date 18.11.1997.

107. Patent 5688741 US.Carrazza J., Pereira P., Martinez N. Process and catalyst for upgrading heavy hydrocarbon. Publ. Date 18.11.1997.

108. Pereira P., Marzin R., Zacarias L., Córdova J., Carrazza J., Marino M. Steam conversion process and catalyst. 5885441, 1999.

109. Fathi M.M., Pereira-Almao P. Catalytic aquaprocessing of arab light vacuum residue via short space times. Energy and Fuels 2011. Vol. 25(11), P. 4867-4877.

110. Cabrales-Navarro F.A., Pereira-Almao P. Catalytic Steam Cracking of a Deasphalted Vacuum Residue Using a Ni/K Ultradispersed Catalyst. Energy \& Fuels 2017. Vol. 31(3), P. 3121-3131.

111. Fumoto E., Tago T., Tsuji T., Masuda T. Recovery of Useful Hydrocarbons from Petroleum Residual Oil by Catalytic Cracking with Steam over Zirconia-Supporting Iron Oxide Catalyst. Energy \& Fuels 2004. Vol. 18(6), P. 1770-1774.

112. Fumoto E., Sato S., Takanohashi T. Catalytic Cracking of Heavy Oil over a Complex Metal Oxide Catalyst in a Steam Atmosphere. In: Nanocatalysis for Fuels and Chemicals, Vol. 1092, Washington, DC: American Chemical Society; 2012, P. 75-85. 
113. Machín I., de Jesús J.C., Rivas G., Higuerey I., Córdova J., Pereira P. et al. Theoretical study of catalytic steam cracking on a asphaltene model molecule. Journal of Molecular Catalysis A: Chemical 2005.Vol. 227(1-2), P. 223-229.

114. Masuda T., Kondo Y., Miwa M., Shimotori T., Mukai S.R., Hashimoto Ket al. Recovery of useful hydrocarbons from oil palm waste using $\mathrm{ZrO}_{2}$ supporting $\mathrm{FeOOH}$ catalyst. Chemical Engineering Science 2001. Vol. 56(3), P. 897-904.

115. Fumoto E., Matsumura A., Sato S., Takanohashi T. Recovery of Lighter Fuels by Cracking Heavy Oil with Zirconia-Alumina-Iron Oxide Catalysts in a Steam Atmosphere. Energy \& Fuels 2009. Vol. 23(3), P. 1338-1341.

116. Funai S., Fumoto E., Tago T., Masuda T. Recovery of useful lighter fuels from petroleum residual oil by oxidative cracking with steam using iron oxide catalyst. Chemical Engineering Science 2010. Vol. 65(1), P. 60-65.

117. Fumoto E., Sugimoto Y., Sato S., Takanohashi T. Catalytic Cracking of Heavy Oil with Iron Oxide-based Catalysts Using Hydrogen and Oxygen Species from Steam. Journal of the Japan Petroleum Institute 2015. Vol. 58(5), P. 329-335.

118. Fumoto E., Sato S., Takanohashi T. Production of Light Oil by Oxidative Cracking of Oil Sand Bitumen Using Iron Oxide Catalysts in a Steam Atmosphere. Energy \& Fuels 2011. Vol. 25(2), P. 524-527.

119. Fumoto E., Sato S., Takanohashi T. Effect of 1-Methylnaphthalene Solvent on Cracking of Oil Sand Bitumen with Iron Oxide Catalyst in Steam Atmosphere. Journal of the Japan Petroleum Institute 2010. Vol. 53(4), P. 260-261.

120. Fumoto E., Sato S., Takanohashi T. Desulfurization of Heavy Oil with Iron Oxide-based Catalysts Using Steam. Journal of the Japan Petroleum Institute 2015. Vol. 58(5), P. 336-340.

121. Kondoh H., Hasegawa N., Yoshikawa T., Nakasaka Y., Tago T., Masuda T. Effects of $\mathrm{H}_{2} \mathrm{O}$ Addition on Oil Sand Bitumen Cracking Using a $\mathrm{CeO}_{2}-\mathrm{ZrO}_{2}-\mathrm{Al}_{2} \mathrm{O}_{3}-\mathrm{FeO}_{\mathrm{x}}$ Catalyst. Energy \& Fuels 2016. Vol. 30(12), P. 10358-10364.

122. Nguyen-Huy C., Shin E.W. Amelioration of catalytic activity in steam catalytic cracking of vacuum residue with $\mathrm{ZrO}_{2}$-impregnated macro-mesoporous red mud. Fuel 2016. Vol. 179, P. 17-24.

123. Nguyen-Huy C., Shin E.W. Hierarchical macro-mesoporous $\mathrm{Al}_{2} \mathrm{O}_{3}$-supported $\mathrm{NiK}$ catalyst for steam catalytic cracking of vacuum residue. Fuel 2016. Vol. 169, P. 1-6.

124. Nguyen-Huy C., Shin E.W. Oxidative cracking of vacuum residue with steam over NiK/ CeZr-Al catalysts. Fuel 2017. Vol. 192, P. 149-157.

125. Do L.T., Nguyen-Huy C., Shin E.W. NiK/yCe $\mathrm{Zr}_{1-\mathrm{x}} \mathrm{O}_{2}$-macroporous $\mathrm{Al}_{2} \mathrm{O}_{3}$ catalysts for cracking of vacuum residual oil with steam. Applied Catalysis A: General 2016. Vol. 525, P. 23-30.

126. Kondoh H., Tanaka K., Nakasaka Y., Tago T., Masuda T. Catalytic cracking of heavy oil over $\mathrm{TiO}_{2}-\mathrm{ZrO}_{2}$ catalysts under superheated steam conditions. Fuel 2016. Vol. 167, P. 288-294.

127. Khalil U., Muraza O., Kondoh H., Watanabe G., Nakasaka Y., Al-Amer A. et al. Production of Lighter Hydrocarbons by Steam-Assisted Catalytic Cracking of Heavy Oil over Silane-Treated Beta Zeolite. Energy \&Fuels 2016. Vol. 30(2), P. 1304-1309. 